\title{
Problems in Water Environmental Control-Sense and Nonsense in Measurement of Water Protection
}

\author{
Stig Morling \\ Sweco Environment, Stockholm, Sweden \\ Email: stig.morling@sweco.se
}

Received 12 September 2014; revised 8 October 2014; accepted 1 November 2014

Academic Editor: Abdel-Razik Zidan, Mansoura University Faculty of Engineering, Egypt

Copyright (C) 2014 by author and Scientific Research Publishing Inc.

This work is licensed under the Creative Commons Attribution International License (CC BY). http://creativecommons.org/licenses/by/4.0/

(c) (i) Open Access

\begin{abstract}
Water environmental control and process refinement inside a wastewater treatment plant (WWTP) is fundamentally based on sampling, analysis and on-line measurements on water and sludge streams. The problems related to an accurate and reliable control and thus an efficient water protection are addressed in the following. Four different crucial points whenever a sampling and control scheme is planned: 1) Where should a sampling and on-line measurement take place? 2) When should sampling take place? 3) How should the sampling and on-line measurement take place? 4) Which variables should be controlled? Examples are given from different plants demonstrating ways to address the questions. Especially the relevance of the adopted parameter BOD (Biochemical Oxygen Demand) is discussed. It is finally suggested to even abandon the use of BOD as consent variable in favor of on-line measurement of Suspended Solids, Nitrogen and Phosphorous.
\end{abstract}

\section{Keywords}

BOD (Biochemical Oxygen Demand), Flow Control, Measurement, Nitrogen, Nitrification, Phosphorous, Sampling, Suspended Solids

\section{Background}

The issue of operation control or background conditions is by convention not refined to the water environment or water treatment facilities. However, sometimes the lack of focus and respect for the water environment status as a consequence adds to "unneeded problems" that may then increase to more or less "non-reparable" levels.

How to cite this paper: Morling, S. (2014) Problems in Water Environmental Control-Sense and Nonsense in Measurement of Water Protection. Journal of Water Resource and Protection, 6, 1381-1389. 
Researchers and concerned environmentalists would possibly point out the Baltic Sea as an example of "too less and too little" with respect to serious water environment control. The question of measurement and especially the clear demand for controlled and repetitive methods is one of the cornerstones in our empirically based science. The issue of a safe water environment is by no means a "new" discovery. But in order to elaborate efficient work tools, both intellectually and physical devices, a deep understanding of the problems linked to measurement and the credibility in the measurement results is of paramount importance. In this paper, some considerations will be presented both on which pollution indicators we use, and how relevant they are. The paper is limited to discuss the problems as they are found in the field of wastewater treatment control. Further, some examples will be presented from a few plants that will highlight some problems and also the typical pattern of pollution variables in the water environmental field.

Two major different perspectives of water environmental control may be identified in relation to wastewater control:

1) A formal influent and effluent control scheme for a wastewater treatment plant. This matter is governed by authority documents giving the maximum permissible concentrations to be discharged. In some cases, the permissible effluent amounts are accordingly defined. A third definition that is not always given in the consent document is the number of samples that should be included in the defined discharge permit.

2) The second, needed control system may be labelled "internal process control". This control may be seen as one of the most important operation tools for the plant operators. The elaboration and content of this control system is totally the operator's responsibility.

An efficient control at a wastewater treatment plant is based on both a controlled sampling of water and sludge at different points inside the plant, as well as at the inlet and discharge points. Today the use of online, continuously working instruments has increased substantially. These instruments would normally play a multiple role at the plant. This matter is discussed more in detail in the following. However, a comprehensive online instrumentation level will contrast to a large extent with what is found in many plants based on a "low cost wastewater treatment" model. In these latter cases you have to rely on either a sampling program, or portable meters. Another aspect in this matter is the fact that an active process control by means of regulations is intentionally avoided in these "low cost" systems. The basic philosophy is rather to rely on extensive and slowly changing processes.

In this context it is important to repeatedly underline a fundamental fact with respect to wastewater treatment: It should be seen as a very demanding process industry, where the raw material is an ever changing matter with respect to amount and pollutant concentration. The task for the wastewater treatment management is as a matter of fact to operate the plant "even better" when the raw material (incoming wastewater) is worse than "normal". By contrast a classical process industry would quite simply reject raw material with inferior or unsuitable quality. This action is by convention not possible from a wastewater treatment operator. This fundamental circumstance underlines the importance of a well elaborated and reliable internal measurement and control system.

\section{Strategies for Sampling and Measurement}

Regardless of the aim for a sampling or an online process control there are four crucial questions to address when planning the activities or, during the erection to include the active control in the decided installations:

- When should a sampling take place; and should the online measurements be used on a continuous basis or as summarized value over a certain time?

- Where should a sampling take place; and where should an online device be located?

- How should a sampling or measurement be arranged? A second question in relation to "How" are the way and the model of online instrument information used in an active process control.

- Which are the relevant pollution and operation variables that should be analysed and controlled?

All these four points must be clearly addressed prior to an implementation of either a sampling scheme or the integration of online instruments in the selected process. In the following these four points are discussed and illustrated by examples.

\section{Discussion on Sampling and Measurements Problems}

\subsection{When Should Sampling Be Performed?}

Decisive information on the different polluting agents as well as the prevailing wastewater flows and load varia- 
tions are important both in the planning stage as well as during the operation. A very clear circumstance for a municipal wastewater treatment plant is a time related variation of the pollution loads. The "classic" variation often addressed is the variation over 24 hours. For smaller communities the wastewater flow variation at the treatment plant is characterized by two peak flows, one in the morning and a second one in early evening. The night flow is normally found to be minimal and mainly composed of infiltration of water into the sewers. In larger communities with a vast collection system along with a number of pumping stations the peak flows will be attenuated and the night flow will be relatively higher. On the other hand quite different patterns may be found even more relevant for a plant. In Figure 1 is shown the load variation during a week at a suburban plant near Stockholm, Sweden.

The pattern reflects the fact that the town is handling wastewater from day-migrants, working in central Stockholm weekdays, but they use the water facilities at home to a "full" extent only on weekends. Even more "dramatic" fluctuations may be found at for instance skiresort facilities, with a peak flow during a few months during wintertime. Thus the pollution pattern may not be clearly discovered until a thorough investigation of the actual conditions has been performed. The example demonstrates that the question "when should the sampling take place" sometimes has a fundamental importance.

A second example is found in Dhaka, Bangladesh. One of the very few wastewater treatment plants in operation in the country is found in the south-eastern part of the capital. The plant is called "Pagla". The operators exercised a grab sampling model, taking samples at the inlet, upstream the screen and at the discharge point from the primary sedimentation stage. The grab samples were taken at 09:00 hours every day. The analysis at the plant laboratory included both SS (Suspended Solids) and $\mathrm{BOD}_{5}$. The typical results from the sampling and analysis are illustrated in Figure 2.

The demonstrated pattern in the figure is based on in all 44 observations, and the pairs of incoming and discharge BOD observations are from the same day of operation. The observations are sorted with the maximum inlet figure to the left and the minimum inlet figure at the right end of the curve. Thus a direct "effect" of a $\mathrm{BOD}_{5}$-removal at the primary treatment at the plant may be found by comparing the inlet and outlet concentrations? The very clear answer to this question is however "NO!" The superficial conclusion from the given data (and a rather astonishing one) would be that a primary sedimentation is capable of performing a BOD-removal

\section{Diagram 2:1 Specifik föroreningsbelastning som veckovariation vid ett kommuanlt avloppsreningsverk}

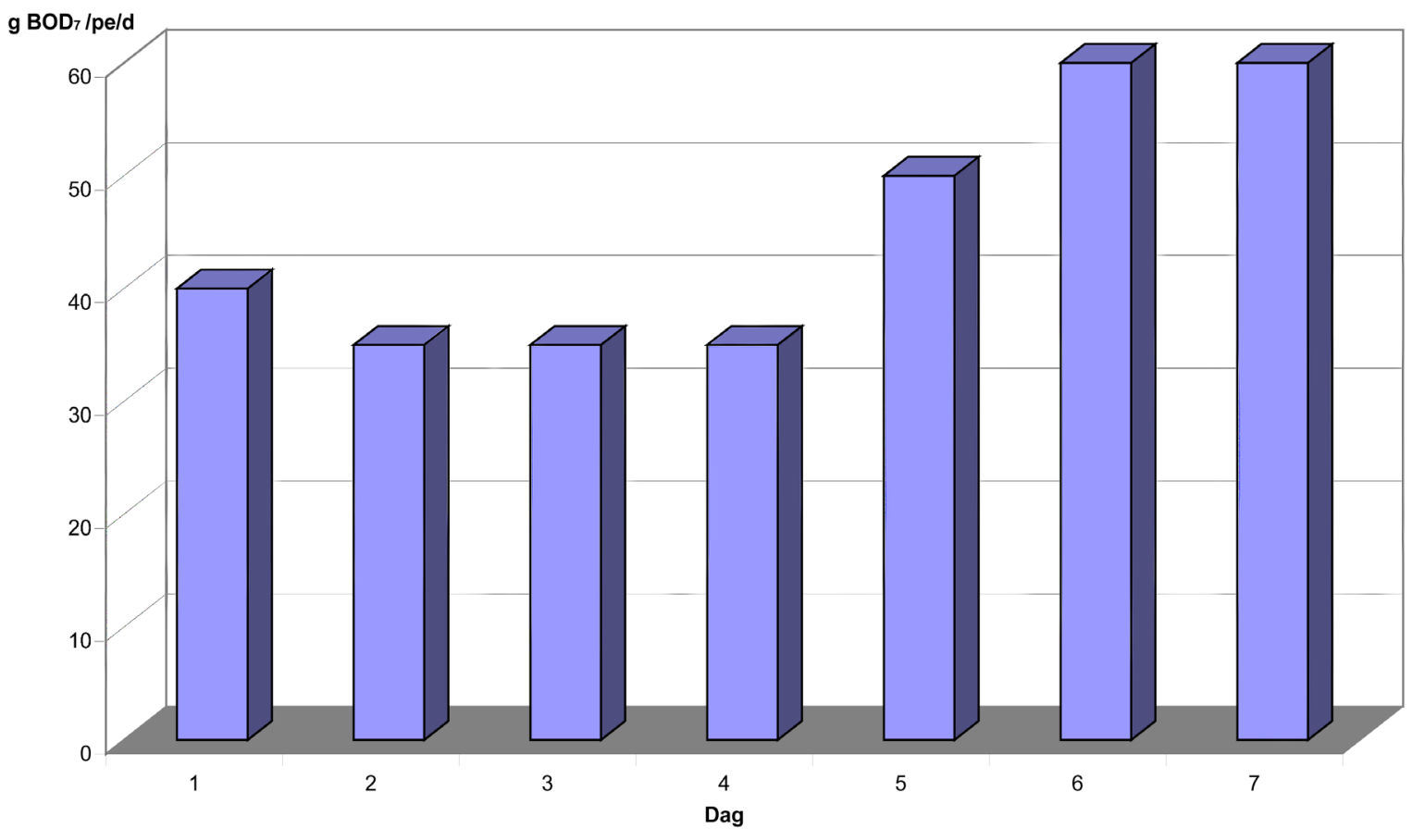

Figure 1. Specific load variation into a suburban Stockholm WWTP (Värmdö community) during a typical week, Monday through Sunday. 


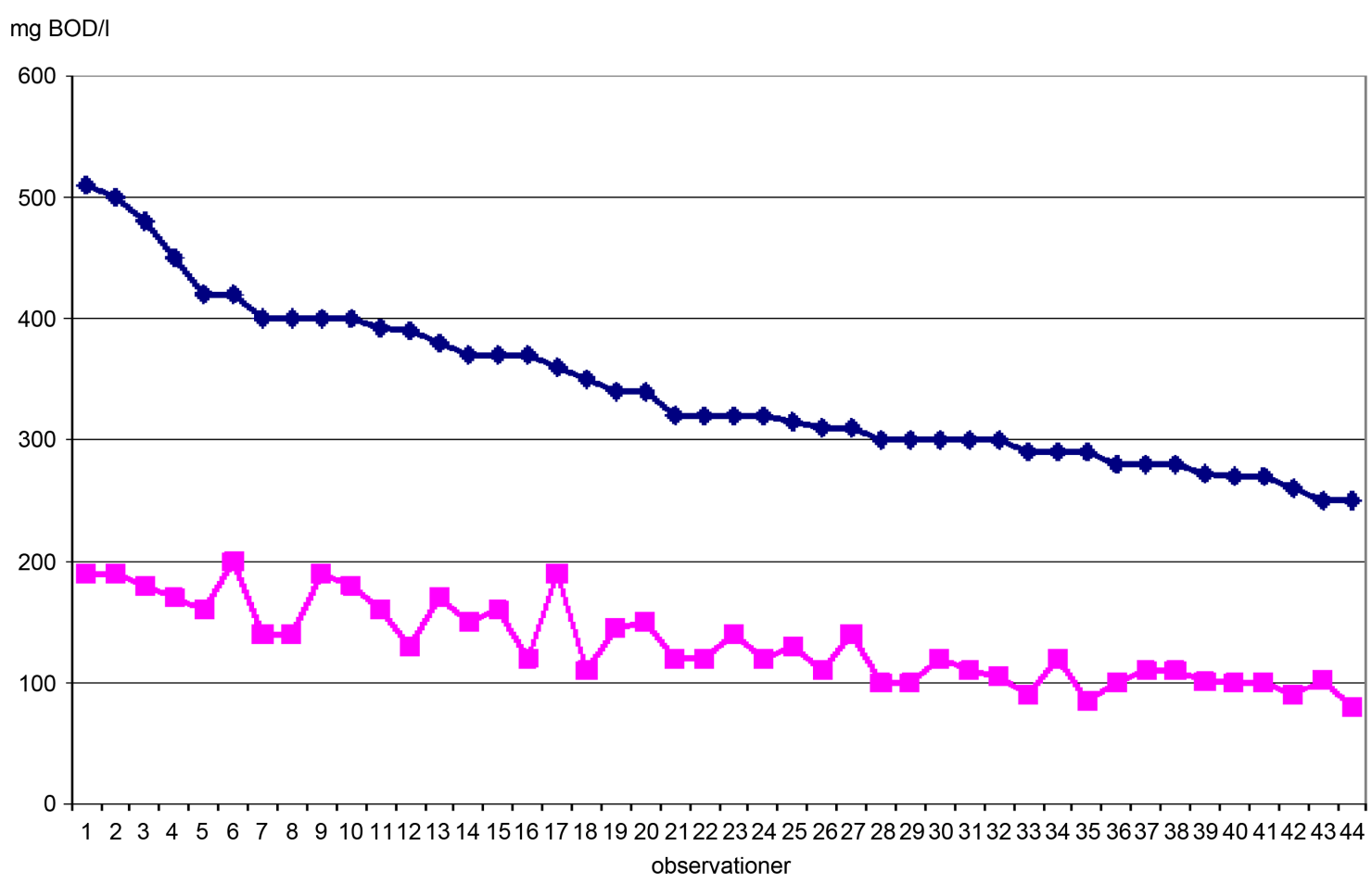

Figure 2. $\mathrm{BOD}_{5}$-concentrations into the Pagla WWTP, Dhaka, and at discharge point from primary sedimentation, based on 44 obs.

of around $60 \%$, and reaching this level without any addition of chemical agent for an improved solids removal! Now, this is the reasonable answer to the question in this matter:

The grab samples at the inlet represent very likely a "peak morning" loads.

The grab samples downstream the primary sedimentation represents wastewater arriving to the plant during nighttime, the average residence time in the primary sedimentation may be several hours.

As a conclusion: These two collections of grab samples do not provide a relevant basis for comparison, or as a ground for performance estimation.

Further interesting examples may be drawn from the Pagla plant; however, these are discussed in a following section.

\subsection{Where Should Sampling Be Performed?}

The second issue is as pointed out: Where should the sampling is done? Again the two different viewpoints of sampling represent sometimes more or less "contradictive" demands when looking at the inlet to a plant. While the "formal environmental control" takes into account the actual "external load" on the plant, the "internal process control" also has to consider the internal side streams that represent secondary pollution. The formal control must by convention be based on the actual and as reliable measurement of the true incoming loads of the plant.

It is imperative to distinguish between these two sampling models, and actually use the gained information only for the relevant purposes:

- The true inlet loading would be seen as a "legal" control, describing the relation between the actual loading and the permissible loading, normally defined in the permit conditions for the plant;

- The "running" total loading into the main treatment plant facilities, used as an important tool and source of information enabling the operator to run the plant as correctly as possible.

In many cases the internal pollution loads may be substantial. This matter is especially true when sludge treatment by anaerobic stabilization (digestion) is operated. The reject water is in this case rich on both dissolved organic matters as well as on hydrolyzed nutrients, occurring as phosphates and ammonia nitrogen. A proper design must in these cases consider an internal loading with respect to ammonia nitrogen of $20 \%-30 \%$ in addition 
to incoming amounts. This circumstance calls for an extra control point inside the plant.

However, the internal process control would normally include a number of additional sampling or on-line control points. In this context it is important to remember that a WWTP almost always represents a "unique" situation with respect to loading and variations. Thus for an internal process control it is imperative to carefully consider and choose the relevant pollution variables when an internal control system is elaborated. In the following some examples of relevant measurement points are given, without the ambition to give a true comprehensive "list". It would be pointed out that some of these control points should have on-line instruments, allowing for an active control and adjustment of the operation as described below:

- A sampling and control point should be located downstream the pre-treatment facilities, normally based on screening and grit/sand removal. It may even be questioned whether this point may be more relevant for an internal process control rather than a sampling of the raw wastewater arriving at the plant. Two reasons support this statement. As indicated above, the internal loads due to recirculating streams may be substantial, and the sampling of raw wastewater may well be disturbed by trash and other coarse matters that limit the availability of the automatic sampler.

- Upstream the biological treatment is more or less imperative in order to provide as adequate data to operate the main biological treatment stage as accurately as possible. The two main objectives for the biological treatment are to perform a sufficiently safe and good discharge quality, and by doing so also as far as possible save energy. The activated sludge system as an example represents often $65 \%$ - $75 \%$ of the total energy consumption at a modern WWTP. The typical pollution variables to control at this point are discussed in the next section;

- Upstream a chemical precipitation stage, in order to as far as possible minimize the needed addition of precipitation agent;

- Internal sampling or online measurement should also be arranged at different internal sludge streams, such as sludge from primary sedimentation, on return activated sludge, and on waste activated sludge, on thickened sludge into an anaerobic digester and/or to the final sludge dewatering system;

- Whenever a final polishing stage is operated, such as a rapid sand filter or a sieving filter screen it is recommended to also control the backwash water quality.

A basic condition for all these suggested points is that they also include (preferably) an on-line flow measurement device.

\subsection{How Should Sampling Be Performed?}

The question "how" should a sampling or on-line measurement be performed has to be addressed already when planning the WWTP. Some crucial conditions must be satisfied, as described in the following.

It may be self-evident to underline that the sampling or control point must represent a "true" situation. Thus, for flow and quality control, the chosen point should represent the whole flow passing this point, and during true turbulent conditions. The turbulent conditions must prevail during the entire sampling time. As an example of the opposite an example from a mid-sized municipal WWTP in central Sweden may be given. The automatic sampler at the discharge point from the plant was located at the main collection channel for treated water. The sample was pumped from the bottom of the channel. The sampling was based on a flow proportional $10 \mathrm{ml}$ samples per pumping, covering 24 hours. During nighttime when the flow was insignificant the small amounts of SS settled on the bottom of the channel were sampled. Thus, the samples pumped during this time had a non-representative high concentration of SS. This in turn resulted in an elevated $\mathrm{BOD}_{7}$-level that gave the false impression of a "non-performing" plant.

It is of especial importance to identify different wastewater streams within the WWTP, and how these streams result in a composition when mixed. This in turn means that it may become necessary to include separate analyses of the different streams. A typical example is when the main stream is treated through all the purification stages in the plant, and a limited excess stream is by-passed (normally the biological treatment). When mixed again it may be found that the resulting discharge flow may not satisfy the effluent consent values. Thus for a sufficiently good "trouble-shooting" it is then necessary to identify the main "problem" by analyzing and estimating the different streams. This in turn calls for a comprehensive sampling and analysis, flow measurement and in the best case also on-line measurements.

Especially for large plants it is rather commonplace that the plant is built in several stages time wise. Sometimes a plant has been built with parallel biological lines to support the, but built with different technologies. An 
example of such a typical model may be found at a major Swedish plant with one older line based on a trickling filter, and a newer one as an activated sludge plant. When scrutinizing such a plant some questions are needed to be raised: To accurately understand the downstream characteristics of the wastewater and to some extent different sampling programs would be exercised. As an example, a trickling filter would in most cases not perform a major nitrification, and the excess biological sludge will pass on to a downstream sedimentation stage. On the other hand an activated sludge plant operated correctly may well perform both nitrification and denitrification, along with a low level of SS in the discharge wastewater. In order to avoid a possible faulty sampling and thus erratic conclusions made it is advisable to address and carefully arrange both flow measurement and adequate sampling/analysis for the different streams.

\subsection{Which Variables Should Be Controlled?}

The classical problems related to the selection of adequate pollution variables are related to a number of "interlinked" issues. These cover not only the accuracy in the analysis methods; where in the treatment chain the control is performed; but also the legal framework that stipulates the effluent conditions. In the following, the use of $\mathrm{BOD}_{5}$ as a key variable for various control and operation issues is addressed.

In most countries the maximum permissible load of the plant is based on a "design population load". This in turn is often expressed in $\mathrm{kg} \mathrm{BOD}_{5} / \mathrm{d}$ or, for municipal WWTP: $\mathrm{s}$ as a maximum allowed population to be connected. The EU directive [1] from 1991 typically underlines this matter, and you may state that the $\mathrm{BOD}_{5} / \mathrm{d}_{\text {-level }}$ has a more or less "paramount" importance in wastewater control. Now you may raise a number of objections to this widespread use. In the following is presented some perspectives where you would find relevant indications of this standpoint. The effluent demands are related to the plant size expressed as the number of person equivalents $(\mathrm{PE})$ connected to the plant. The PE in turn is expressed as $1 \mathrm{PE}=60 \mathrm{~g} \mathrm{BOD} / \mathrm{d}$. For simplistic reasons the PE is often "translated" into physical persons. Now, at least two problems arise in connection to this matter:

1) The BOD analysis is by far the least "accurate" one of the classic pollutants we normally analyzed. The accredited laboratories normally guarantee a result of $\pm 30 \%$ accuracy on a single BOD analysis [2]. Thus this in turn calls for a rather large number of independent BOD analyses to provide a reliable estimate on the inlet load. Statistically the following equation may be applied to find the resulting accuracy of a number of independent observations with a known individual accuracy level, Equation (1). It should be observed that the equation is valid for observations that are stochastically normal distributed. Especially for a limited number of observations within the environmental field a log-normal distribution is sometimes argued to be more relevant [3]. However, as found in the examples presented here the basis for the different examples is a rather large number of observations. This in turn would in most cases justify the assumption to apply a normal distribution.

$$
F= \pm \Delta F / \sum n^{1 / 2}
$$

where

$F=$ resulting accuracy for the total number of Observations $(=n)$;

$\Delta F=$ the accuracy in a single analysis;

$n=$ number of analysis.

This in turn means that if you demand a $\pm 5 \%$ accuracy for a BOD $_{5}$ concentration you will need 36 independent samples tosatisfy this criterion.

2) Now the connection to a plant expressed as number of inhabitants served by the WWTP may well be equal to the formally accepted design number expressed as PE. Nevertheless, the actual loading, expressed as $\mathrm{BOD}_{5}$ may be substantially lower than the accepted organic loading of the plant. Further the plant may be found in good operation conditions, "outperforming" the stipulated effluent demands. Nevertheless the authorities may formally prohibit any additional connections of housing areas to the WWTP. The reason for this may be amis understanding of what a "PE" really represents. This in turn means that the invested facility may not be utilized to its real capacity, and more or less unnecessary bureaucratic actions take place instead of addressing the potential capacity of the plant. The latter option would be seen as a far more sustainable environmentally sound action!

Finally the Pagla WWTP in Dhaka, Bangladesh may illustrate a systematic error with respect to the chosen and not chosen variables. The discharge figures from the Pagla plant are presented in Table 1, demonstrating the effluent values of $\mathrm{BOD}_{5}$ and $\mathrm{SS}$. The table also presents the variation in $\mathrm{SS} / \mathrm{BOD}_{5}$ ratio. 
Table 1. BOD and SS concentrations in effluent water from Pagla WWTP, Dhaka, as well as the ratio SS/BOD 5 for the observations.

\begin{tabular}{cccc}
\hline & SS & BOD & RATIO SS/BOD \\
\cline { 2 - 4 } No of obs. & 35 & 44 & 35 \\
\cline { 2 - 4 } & $\mathrm{mg} / \mathrm{l}$ & $\mathrm{mg} / \mathrm{l}$ & $\mathrm{mg} / \mathrm{l}$ \\
\hline Max. value & 72 & 140 & 1.2 \\
Mean value & 50 & 87 & 0.57 \\
Median value & 48 & 90 & 0.55 \\
Min. value & 30 & 50 & 0.29 \\
Standard error & 11.42 & 20.52 & 0.19 \\
\hline
\end{tabular}

From a statistical point of view the figures presented may be found more or less a normal "picture" of the relation. However, from a process engineer's point of view there are evident errors, when considering that the treatment system includes a four stage biological pond system. This clearly would indicate that the $\mathrm{BOD}_{5}$ discharge level would be almost insignificant. From a process point of view the soluble BOD after a comprehensive biological treatment would be insignificant. The remaining BOD thus found as particulate organics. A reasonable true ratio of $\mathrm{SS} / \mathrm{BOD}_{5}$ in such cases would be $>2: 1$. Now what may be the grounds for the erratic results? The classical answer is that a nitrification of the ammonia nitrogen probably has taken place. This in turn affects the (carbonaceous) BOD analysis. Thus the operators at the plant were encouraged to include analysis of inorganic nitrogen into the standard control procedure. The following spring a comprehensive analysis of $\mathrm{NH}_{4}-\mathrm{N}$ and $\mathrm{NO}_{3}-\mathrm{N}$ was performed. A nitrogen reduction over the oxidation ponds was revealed-between $40 \%$ and $85 \%$. The presence of nitrate nitrogen was found. However, for the BOD-analysis no addition of inhibitor for nitrification was added in the standard analysis at the plant. Thus the lack of a correct and more comprehensive analysis program was demonstrated, and a systematically erratic BOD-effluent level had been recorded for a long period. In this case two conclusions may be drawn: The very frequent analysis of BOD failed to present a realistic discharge situation; the absence of nitrogen analysis resulted in a failure for a deeper understanding —at least for a time-of the plant performance.

An additional perspective on the "over-emphasis" of the BOD control is given by studying an example from a mid-sized Swedish plant. In Figure 3 is shown the discharge levels of the $\mathrm{BOD}_{7}$ from the plant that incorporates advanced organic removal, biological nitrogen removal and chemical/enhanced phosphorus removal. Further description of the treatment performance at this plant has been presented previously [4]. The figure is based on 48 observations, whereof one single observation is >the accepted consent level of $10 \mathrm{mg} \mathrm{BOD} / \mathrm{l}$; all the other 47 observations are at or below $3 \mathrm{mg} \mathrm{BOD} / 1$. Now you may ask is there really a need to use this variable as a consent value?

By contrast the effluent pattern for phosphorus shows a very different pattern. In Figure 4 is shown the effluent levels from the Nowy Targ WWTP in southern Poland. Further information regarding the Nowy Targ WWTP is found in [5].

The question on appropriate and relevant control variables may further be enlightened by using the Oxidation Consumption Potential (OCP) equation. This relation was suggested by prof. Halvard Ödegaard, at the Norwegian Technical University in Trondheim, and later used in several reports [6]-[8]; Equation (2):

$$
\mathrm{OCP}=1 * \mathrm{BOD}+4 * N_{\text {prim }}+14 * N_{\text {secondary }}+100 * N_{\text {secondary }}
$$

where

OCP = Oxygen Consumption Potential, in $\mathrm{kg} \mathrm{O}_{2} / \mathrm{d}$;

$1 * \mathrm{BOD}=$ the oxygen demand expressed by BOD, equals 1 by convention, in $\mathrm{kg} \mathrm{O}_{2} / \mathrm{d}$;

$4 * N_{\text {prim }}=$ Primary oxygen demand due to the oxidation of nitrogen compounds into nitrate, in $\mathrm{kg} \mathrm{O}_{2} / \mathrm{d}$;

$14 * N_{\text {secondary }}=$ Secondary oxygen demand due to the algae production and decrease, caused by nitrogen, in $\mathrm{kg} \mathrm{O}_{2} / \mathrm{d}$;

$100 * N_{\text {secondary }}=$ Secondary oxygen demand due to the algae production and decrease, caused by phosphorous, in $\mathrm{kg} \mathrm{O}_{2} /$ d. 


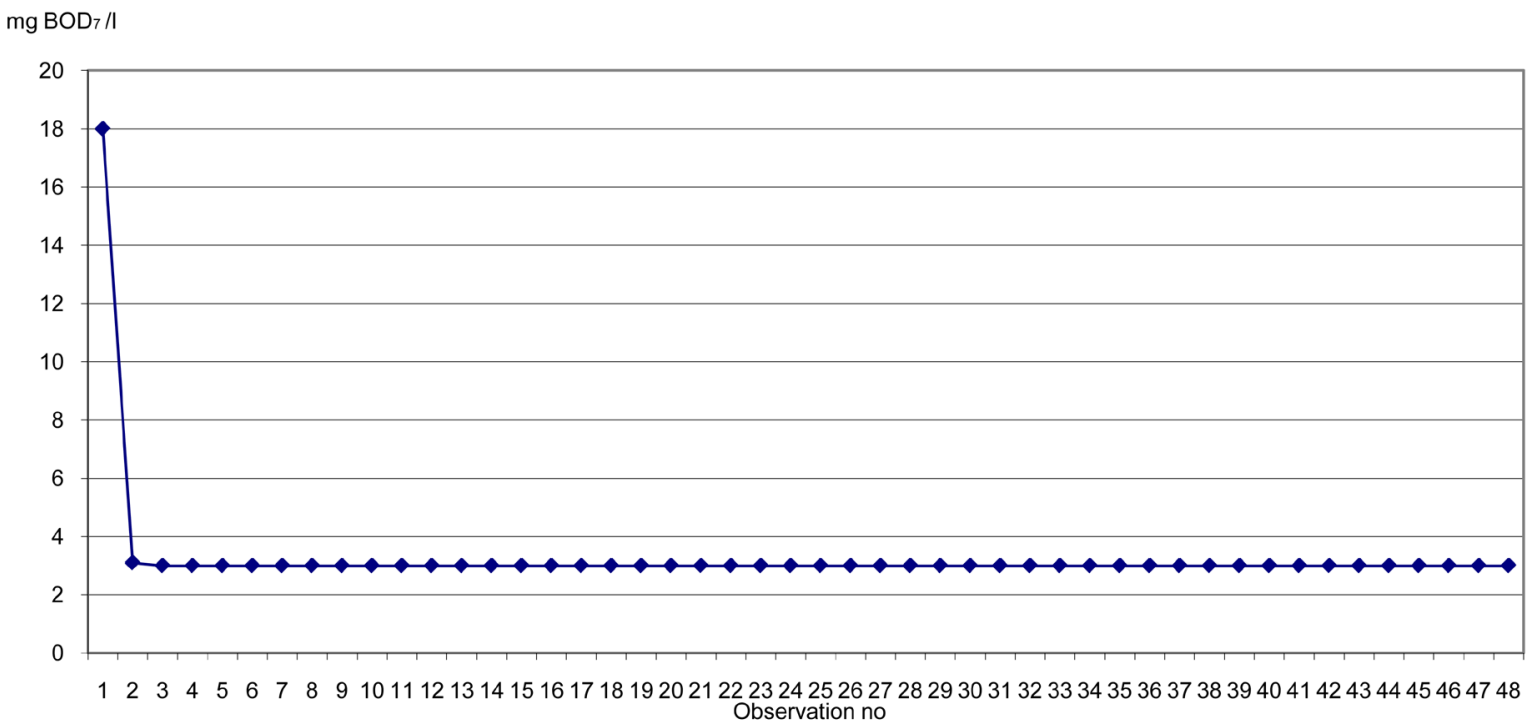

Figure 3. Discharge levels of $\mathrm{BOD}_{7}$-concentrations from a WWTP in the Greater Stockholm area, (Värmdö community), covering one year operation, based on 48 obs.

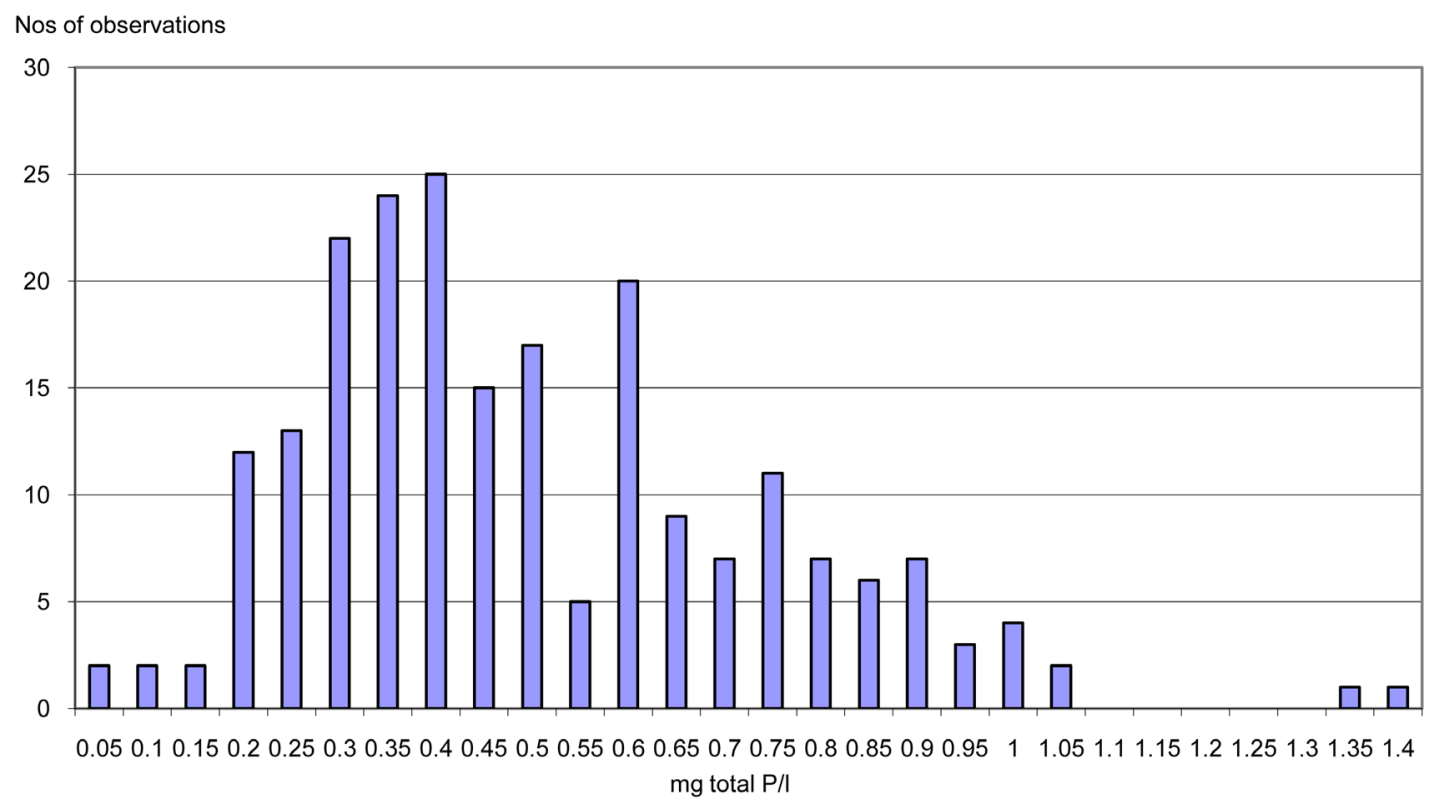

Figure 4. Discharge pattern regarding phosphorus from two years operation of the Nowy Targ WWTP, in all 211 observations.

As may be concluded from the OCP relation the BOD influence is limited compared with nitrogen och phosphorus. When controlling a municipal WWTP discharge including nutrient removal it would be far more fruitful to concentrate on the nutrient compounds when stating the appropriate consent values.

\section{Conclusion}

The current very limited interest and understanding of water environment control as reflected in wastewater treatment is far from acceptable. It is remarkable that we still use such an indirect and imprecise model to characterize both loading and effluent quality as the BOD. Apart from the already quite well understood needs for an improved control of nutrients, we will need additional and better reflecting variables to meet our forthcoming 


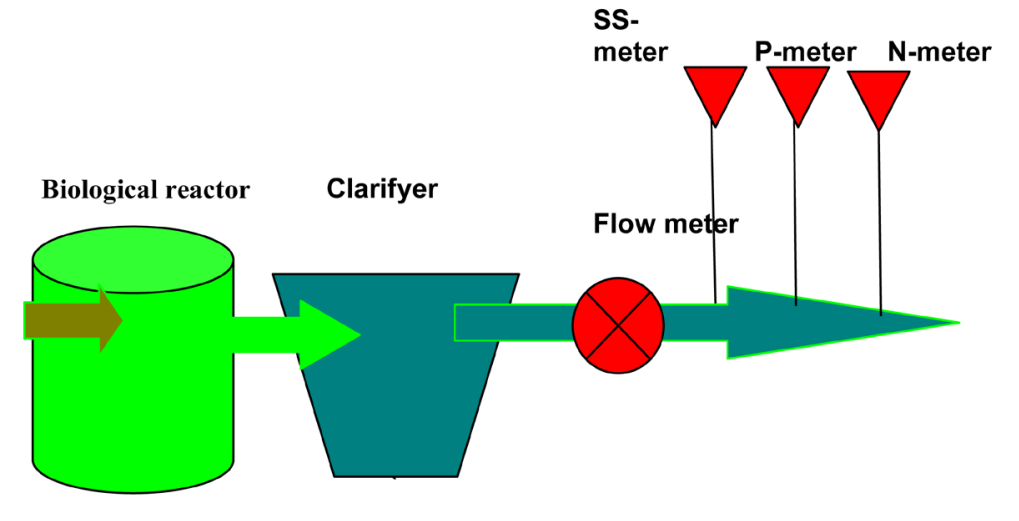

Figure 5. Possible model for a future continuous quality control on effluents from a municipal WWTP.

needs of a better wastewater control. In this context, it may be sufficient to point out the number of complex polluting agents, for example, the variation of pharmaceutics found in the municipal wastewaters. A first stage towards an improved measurement status and more reliable control would be to install on-line meters on the effluent, as illustrated in Figure 5. In the future, there will very likely become needs for additional control systems and refined legal frameworks.

\section{Acknowledgements}

The text has been scrutinized with respect to comments on statistical issues by Mr. Per-Lennart Karlsson, who has taken his time to correct and clarify some aspects, thank you. Mr. Guy Taylor has been helpful in analyzing the linguistic matters in the paper, most valuable!

\section{References}

[1] European Union (1991) Council Directive 91/271/EEC Concerning Urban Waste Water Treatment.

[2] Alcontrol Analysis Protocols. http://se.alcontrol.com/sv/

[3] Olsson, U. (2005) Confidence Intervals for the Mean of a Log-Normal Distribution. Journal of Statistics Education, 13. www.amstat.org/publications/jse/v13n1/olsson.html

[4] Morling, S. (2001) Performance of an SBR-Plant for Advanced Nutrient Removal, Using Septic Sludge as a Carbon Source. Water, Science and Technology, 43, 131-138.

[5] Morling, S. (2008) Nitrogen Removal Efficiency and Nitrification Rates at the Sequencing Batch Reactor in NowyTarg, Poland. VATTEN, 2.

[6] Karlsson, I. (1996) Environmental and Energy Efficiency of Different Sewage Treatment Systems. Water, Science and Technology, 34, 203-211. http://dx.doi.org/10.1016/0273-1223(96)00575-6

[7] Helsinki Commission (2007) Background Information on Costs for the Revised Proposal from Sweden Concerning More Stringent Demands Regarding Discharges of Phosphorus from Waste Water Treatment Plants.

[8] Umble, A.K. (2010) Nutrients and Technologies That Remove Them. Indiana Water Environment Association. 
Scientific Research Publishing (SCIRP) is one of the largest Open Access journal publishers. It is currently publishing more than 200 open access, online, peer-reviewed journals covering a wide range of academic disciplines. SCIRP serves the worldwide academic communities and contributes to the progress and application of science with its publication.

Other selected journals from SCIRP are listed as below. Submit your manuscript to us via either submit@scirp.org or Online Submission Portal.
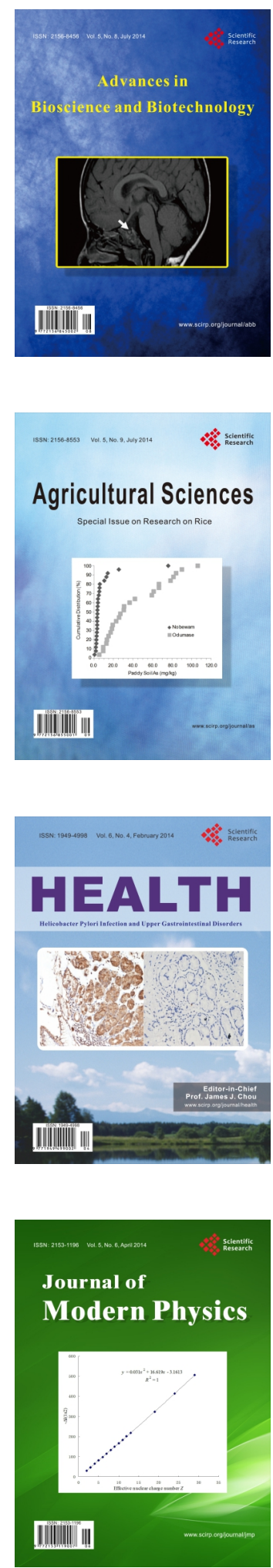
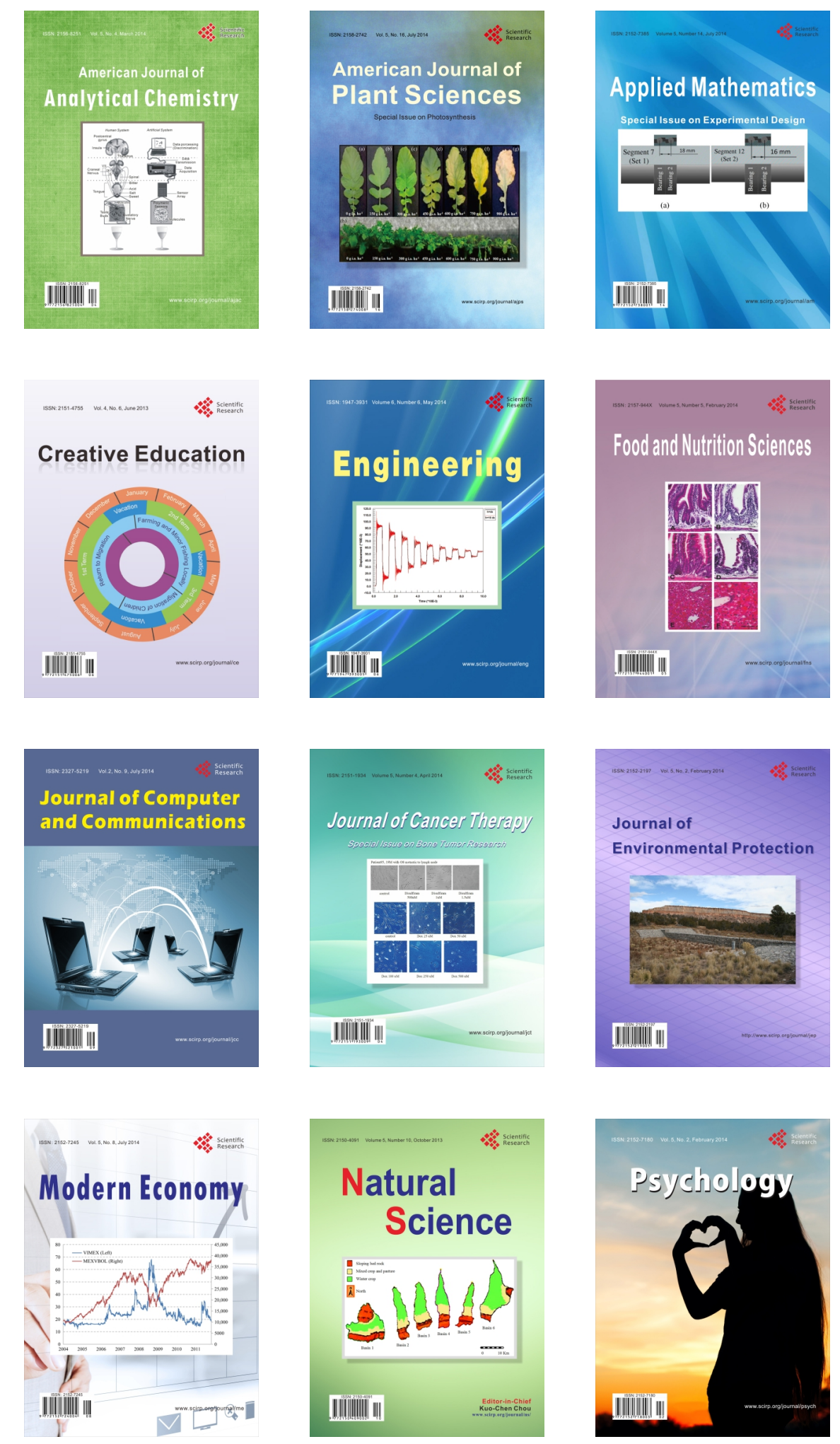